\title{
Modeling Enterprise Risk Management in Operations and Supply Chain: A Pharmaceutical Firm Context
}

\author{
Chris I. Enyinda \\ School of Business Administration, \\ Canadian University Dubai, Dubai, UAE \\ Email: christian@cud.ac.ae
}

\begin{abstract}
The growing prevalence of disruptive influences in modern operations and supply chains has called for a systematic approach to identify risk sources and to develop predictive enterprise risk management. This imperative has become a top priority for many organizations such as the pharmaceutical industry. This paper leverages a multi-criteria decision making methodology to model enterprise risk management in a focal pharmaceutical firm operations and supply chain. Six types of risks and five strategies are considered and analyzed. Results suggest that supply chain executives attach great importance to regulation/legislation, followed by operational, and reputation risks, while financial, market, and relationship risks ranked low in importance. With respect to enterprise risk management strategies, risk reduction/mitigation was considered the best option followed by risk avoidance option. From the results, it appears that multicriteria decision making methodology can be used to assist supply chain executives in developing a priority hierarchy for risk management strategies. It can also help the management with a step-by-step approach to identify, assess, and manage portfolio of risks that can be detrimental to their pharmaceutical supply chain performance, brand equity, profit growth, and shareholder value.
\end{abstract}

Keywords: pharmaceutical supply chain risk, multi-criteria decision, risk management strategies

\section{INTRODUCTION}

The pharmaceutical industry global supply chain has grown in recent years (wood et al. 2008) because of the pursuit for low cost commodities and services. Although today's global marketplace offers pharmaceutical firms low costs for many commodities and services, they are faced with daunting challenges of managing their supply chain operations that have increasingly become complex and convoluted nature. The convoluted nature of the pharmaceutical global supply chain renders it vulnerable to both predictable and unpredictable risks. All types of risks exist within supply chains (Lee et al. 1997) and organizations face them whenever they seek goods and services to meet their goals and objectives (Zsidisin et al. 2004) and when there is a high propensity that an event can take place and result in a significant disruption (Hallikas et al. 2002; Yates and Stone 1992). Therefore, to sustain differentiated competitive advantage in the new economy, organizations must be able to manage uncertainty and risks by building flexible and smart supply chains that can sense and respond to a changing business environment. According to Breen (2008), pharmaceutical supply chain risks can be associated with shortage or discontinuation product, poor performance, patient safety/dispensing errors, and technological errors. Also, pharmaceutical global supply chain risk that is not assessed and managed proactively can lead to patient harm and death, product recalls, loss of integrity, and significant financial liability for a firm (Wood et al. 2008).

Indeed, the pharmaceutical supply chain C-level executives are facing ever growing uncertainty and risk within and across trade borders. Arguably, the spate in the pharmaceutical supply chain risks and the accompanying pressure from regulatory bodies, changing legislation, exchange rate, customers, and competition are forcing many forward-looking pharmaceutical organizations to implement enterprise (or supply chain) risk management. Some of the advantages of supply chain risk management include fewer surprises, better decision making, improved balance between opportunity and risk, enhanced competitive advantage, and managing suppliers more effectively (O’Brien and Joyce 2007).

Risks that are unmitigated can precipitate to production and distribution delays which in turn can take a significant toll on supply chain profitability, shareholders' wealth and supply chain confidence. Implementing enterprise risk management can offer firms greater opportunity to improve their understanding of the potential sources of risk and their impact on supply chain disruption. Thus, for organizations to optimize their supply chain performance and profitability, it "requires ongoing analysis of the key risks spanning the entire [supply chain] that connects suppliers, manufacturers, distributors, retailers and customers" (Lowery 2004, p. 2).

In this study, a multi-criteria method known as analytical hierarchical process (AHP) model developed by Saaty (1980) is utilized in which the goal being pursued has multiple, often conflicting attributes. AHP is a multi-criteria decision making process which enables decision makers set priorities and deliver the best decision when both quantitative and qualitative aspects of a decision must be considered. Advantages attached to AHP include its reliance on easily derived expert judgment data, ability to reconcile differences (inconsistencies) in expert judgments and perceptions, and the existence of Expert Choice Software that implements the AHP (Calantone et al. 1989).

The rest of this paper is structured is as follows: Section 
2 presents a brief review of literature; Section 3 discusses the research methodology; Section 4 describes the data collection; Section 5 presents the research findings and discussion; and Section 6 is about the conclusions and managerial implications. This paper contributes to literature by shading light on the growing importance of risk mitigation in global supply chain of a focal pharmaceutical firm.

\section{LITERATURE REVIEW}

\subsection{Risk, Risk Sources, and Supply Chain Risk Management}

Risk has been viewed as a combination of the probability of an event and its effects (e.g., Norrman and Jasson 2004; Jüttner et al, 2003). Others have classified risk into probability, impact and importance (e.g., Hunter et al., 2004; Hallikas et al., 2004). Kleindorfer and Saad (2005) assert that the two major categories of risk that can disrupt supply chain design and management are 1) risks emanating from the challenges of coordinating supply and demand and 2) risks associated with disruptions to normal functioning of activities. Supply risk poses a key challenge to supply chain management (Trkman and McCormack 2009). Supply chain disruptions risk is as result of a firm's inability to match demand and supply (Hendricks and Singhal 2005).

Emerging and existing supply chain disruptive influences pose an increasingly significant risk to pharmaceutical operations and supply chains performance. Sources of risk that can disrupt pharmaceutical operations and supply chains superior performance include regulation and legislation, operation, reputation, financial, market, relationship, counterfeit, regulatory agencies, intellectual property infringement, currency fluctuation, exchange rate, supplier failure, underdeveloped product pipeline, and legal liability (e.g., Hillman and Keltz 2007; Chan et al. 2002; KPMG 2005).

A growing number of studies have been focusing on supply chain risk management (e.g., Tang 2006; Gaudenzi and Borghesi 2006; Hendricks and Singhal 2005; Cavinato 2004; Kleindorfer and Saad 2005; Towill 2005; Barry 2004; Christopher and Lee 2004; Zsidisin et al. 2004; Spekman and Davis 2004; Hallikas et al. 2002; Johnson 2001; Souter 2000). All types of risks exist within supply chains (Lee et al. 1997) and organizations face them whenever they seek goods and services to meet their goals and objectives (Zsidisin et al. 2004). Arguably, there still exist research gap in the operation and supply chain management literature, most importantly risk management in the pharmaceutical operations supply chain. Thus, presenting little research in terms of enterprise risk management in pharmaceutical operations and supply chains leveraging Saaty's (1980) AHP model and performing sensitive analysis. However, there is one study that uses AHP in managing risk in supply chain management in a non-pharmaceutical firm. For example, Gordensi and Borghesi (2006) applied AHP to evaluate risks attached to supply chain. Based on the preceding, there is an opportunity to develop research in a different industry such as the pharmaceutical industry in order to gain improved understanding in this area.

Bandyopadhyay et al. (1999) reported that key components of risk management include 1) risk identification, 2) risk analysis, 3) risk reduction, transfer and acceptance, and 4) risk monitoring. Pharmaceutical supply chain risk mitigation strategies considered in this paper includes mitigate/reduce, avoid, retain, and share risks.

Most decision-making environments entail multiple criteria. And the evaluation and management of pharmaceutical supply chain outsourcing risk represents a typical multi-criteria decision making (MCDM) problem that entails conflicting criteria that can be both qualitative and quantitative. AHP has been used effectively to model different types of MCDM problems (Saaty, 1980). Arguably, the AHP model is proposed and used in this study to model enterprise risk management in a focal firm's pharmaceutical operations and supply chain. The AHP model is selected because it allows decision-makers to model a complex problem in a hierarchical structure portraying the relationships of the overall goal, criteria (objectives), subcriteria (sub-objectives), and alternatives. Although the positive attributes associated with AHP has been widely reported in the operation and supply chain management literature, there has been a small number of descending opinions (e.g., Belton and Gear 1986; Dyer and Wendel 1985). However, in defense of Saaty's AHP, Perez (1995) proved that their criticisms against AHP method were not valid. Because of its usefulness, AHP has been widely used in countless number of studies. Some studies that have used AHP include international business management (e.g., Atthirawong and MacCarthy 2005), operations and supply chain management (e.g., Gaudenzi and Borghesi 2006; Min 1992); marketing (Dyer and Forman 1992); pharmaceutical marketing (e.g., Ross and Nydick 1994).

For a pharmaceutical firm to remain viable in today's risky global business environment, it is imperative for it to implement enterprise risk management. Supply chain risk management benefits include better decision making, an improved balanced between risk (threat) and opportunity, enhanced competitive position (O'Brien and Joyce 2007), achieve greater mutual understanding of the interests and problems of all supply chain members. Lack of appropriate risk mitigation can erode public health confidence and reputation, patients' health and safety, and reduction in profit margin and shareholder value.

\subsection{Sensitivity Analysis}

Expert Choice Software is user friendly. It supports the AHP-based sensitivity analysis (SA) scenarios. Decision makers can perform SA to examine the response of the overall utility of alternative course of actions (e.g., risk management options) to changes in the relative importance of each attribute. Rappaport (1967) argues that in the face of risk and uncertainty, the most recurring questions that must be addressed by organizations are of the form, "what if"? "What if" analysis or the so called SA is a technique used to assess how possible changes in parameter values impact model outputs and helps to facilitate a better understanding of risk (Rappaport 1967). Rappaport (1967) asserts that from the humble beginning of business development that decision makers have leveraged SA tests for evaluating relative risk of alternative courses of action. Min (1992) contends that SAs are vital because changing the importance of attributes will require different levels of resource commitment by an organization. Thus, SA can enable a group of decision 
makers to assess what may happen if the priority weights of the attributes change. SA is a means of investigating the impact of reasonable changes in base-case assumptions (Eschenbach 1992) or an approach that allows decision makers to explore impact on the optimal decision(s) of potential changes in any of the problem variables (Trueman 1974). Some of the uses of SA include determining the impact on the ranking of alternatives of changes in various model assumptions, making better decisions, deciding which data estimates should be refined before making a decision, and enabling management to focus attention on the most critical elements during decision implementation (Kirkwood 1997; Eschenbach 1992; Fiacco 2003)).

Triantaphyllou and Sanchez (1997) have argued that data in multi-criteria decision making (MCDM) problems are often imprecise and changeable. As a result, an essential step in many uses of MCDM such as AHP is to execute an SA on the weights of the decision objectives and performance values of the alternative options expressed in terms of the decision objectives (Triantaphyllou \& Sanchez 1997). Samson (1988) suggests that SA is a quintessential part of decision making process in real time and generally involves checking the effects of the model assumptions on the model solution. Because of SA's importance in decision making, it has been applied in such areas as pharmaceuticals, medicine, civil engineering, political science and computer science (Steenland and Greenland, 2004; Blake et al., 1988; Castillo et al., 2006).

\section{RESEARCH METHODOLOGY}

\subsection{Structuring supply chain risk problem for AHP model}

Risk mitigation encompasses four components, including problem definition; identification of criteria and sub-criteria; identification of risk control measures; and selection of the best risk management strategy. The alternative enterprise risk management strategies are evaluated based on a set of criteria. In effect, enterprise risk mitigation in a pharmaceutical supply chain is a multicriteria problem that considers both qualitative and quantitative variables and can be solved effectively using AHP. The AHP methodology decomposes a problem and performs pair-wise comparison of all the elements. To demonstrate this approach, a focal pharmaceutical firm is used a case study. The firm identified a total of six supply chain risk criteria and eleven risk sub-criteria. The identified risks include regulation and legislation risk (RLR), operational risk (OPR), reputation risk (RR), financial risk (FR), market risk (MR), and relationship risk (RER). The risk sub-criteria associated with each major risk criteria include regulatory approval (RA), change in legislation (CL), distribution (DI), R\&D (RD), corporate social responsibility (CSR), Disclosure (DIS), exchange rate (ER), competition (CO), key talent (KT), third party logistics (3PL), merger and acquisition (M\&A). Five risk management strategies are also identified and used by this firm to mitigate supply chain risks. Based on six risk criteria, 11 sub-criteria, and five risk management alternatives, the decision hierarchy for the pharmaceutical firm global supply chain risk mitigation is depicted in Figure 1. We then follow Saaty's (1980) recommended steps to map the firm's supply chain mitigation decision making as hierarchy structure fit for AHP methodology. The recommended steps are briefly explained next and include: (1) Clearly state the decision problem and the overall goal; (2) Structure the hierarchy from top through the intermediate levels to the lowest level; and (3) Construct a set of pair-wise comparison matrices for each of the lower levels.

\subsection{AHP Steps (1) and (2)}

In Figure 1, level 1 (Goal) is to mitigate a focal firm's pharmaceutical operations and supply chain risk. The Criteria which are the major supply chain risks are contained

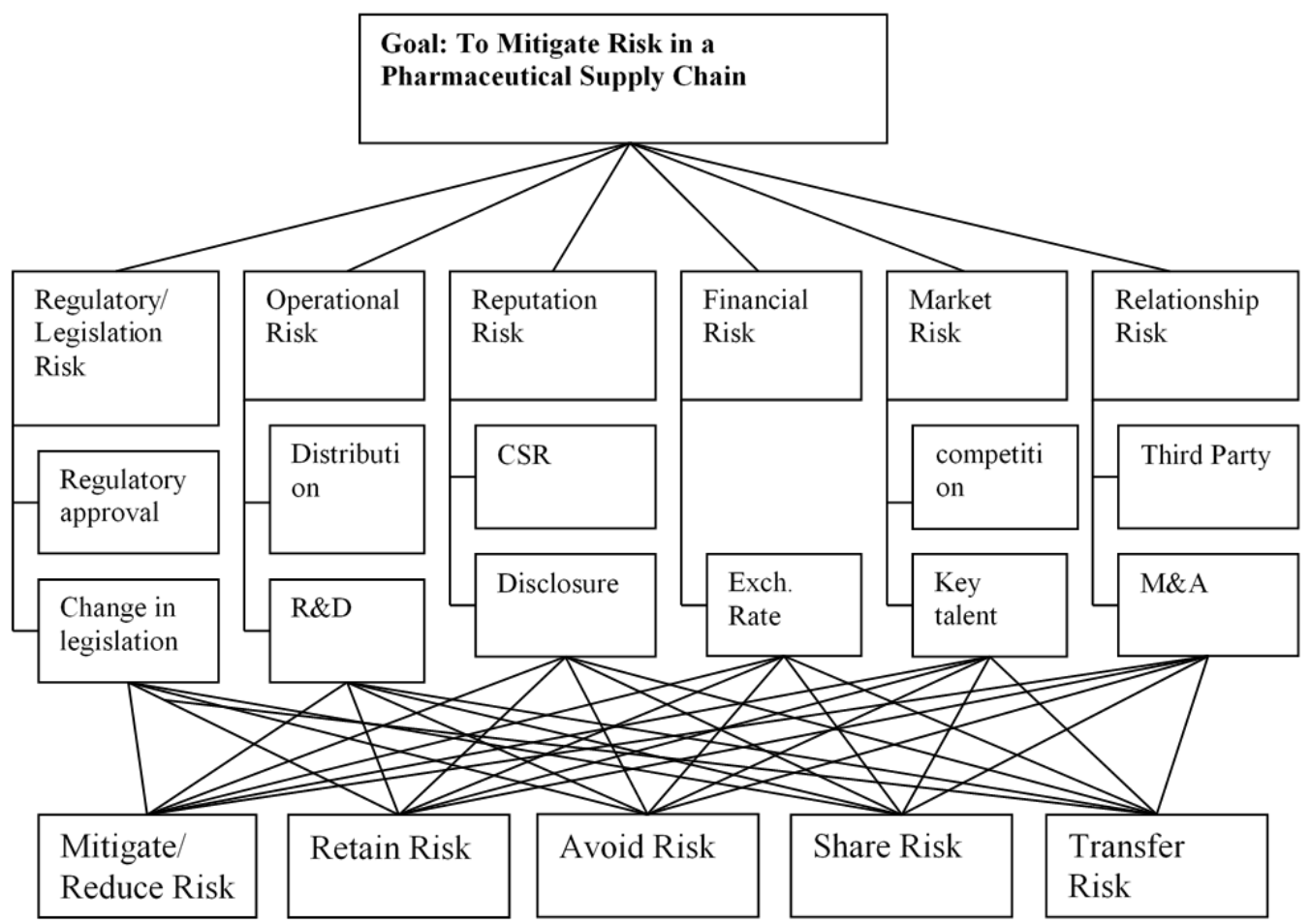

Figure 1 Hierarchy Structure of a Pharmaceutical Firm Global Supply Chain Risk 
in level 2. The supply chain sub-risk factors are reported in level 3. Finally, the alternative enterprise risk management strategies are contained in the last level. The alternative enterprise risk management strategies include 1) transferring risk to another entity willing to assume risk through purchasing of an insurance policy or opting for a forward contract, 2) reducing risk by adopting appropriate internal controls, 3) avoiding risk by way of not engaging in risky business operations, 4) retaining risk either by avoiding the cost of trying to reduce risk or in anticipation of improving profits by assuming additional risk, and 5) sharing risk by pursuing a middle path between retaining risk and transferring risk. These strategies are commonly used in risk management situations and have been validated by previous studies. According to Flanagan and Norman (1993) and Lowe and Whitworth (1996), response strategy to risk can be achieved through risk reduction; risk avoidance; risk transfer; and risk retention.

\subsection{AHP Step (3)}

The third step in using AHP is to construct a set of pairwise comparison matrices for each of the lower levels. The pairwise comparison is made such that the attribute in row $i$ $(i=1,2,3,4 \ldots n)$ is ranked relative to each of the attribute represented by $n$ columns. The pair-wise comparisons are done in terms of which element dominates another (i.e. based on relative importance of elements). Some senior managers who are familiar with the firm's operations and supply chain were asked to perform the pair-wise comparisons and are referred to as judges. Their judgments are then expressed as integer values 1 to 9 in which $\mathrm{a}_{i j}=1$ means that $i$ and $j$ are equally important; $\mathrm{a}_{i j}=3$ signifies that $i$ is moderately more important than $j ; \mathrm{a}_{i j}=5$ suggests that $i$ is strongly more important than $j ; \mathrm{a}_{i j}=7$ indicates that $i$ is very strongly more important than $j ; \mathrm{a}_{i j}=9$ signifies that $i$ is extremely more important than $j$;

Assuming $\mathrm{C}_{1}, \mathrm{C}_{2}, \mathrm{C}_{3}, \ldots \mathrm{C}_{n}$ to be the set of elements and $\mathrm{a}_{i j}$ representing a quantified opinion or judgment on a pair of elements $\mathrm{C}_{i}, \mathrm{C}_{j}$. The relative importance of two elements $\mathrm{C}_{i}$, $\mathrm{C}_{j}$ is assessed using a preference scale on an integer-valued 1-9 developed by Saaty (2000) for pairwise comparisons.

According to Saaty, a value of 1 between two criteria indicates that both equally influence the affected node, while a value of 9 indicates that the influence of one criterion is extremely more important than the other. It allows the transformation of qualitative judgments and/or intangible attributes into preference weights (level of importance) or numerical values. The pairwise comparisons are accomplished in terms of which element dominates or influences the order. AHP is then used to quantify these opinions that can be represented in $n$-by- $n$ matrix as follows:

$$
\begin{aligned}
\mathrm{A}=\left[\mathrm{a}_{i j}\right]=w_{i} / w_{j}= & {\left[\begin{array}{cccc}
w_{1} / w_{2} & w_{1} / w_{2} & \ldots & w_{1} / w_{n} \\
w_{2} / w_{1} & w_{2} / w_{2} & \ldots & w_{2} / w_{n} \\
\cdot & \cdot & \cdot & \cdot \\
\cdot & \cdot & \cdot & \cdot \\
\cdot & \cdot & \cdot & \cdot \\
w_{n} / w_{1} & w_{n} / w_{2} & \ldots & w_{n} / w_{n}
\end{array}\right] } \\
& =\left[\begin{array}{cccc}
1 & a_{12} & \ldots & a_{i n} \\
1 / a_{12} & 1 & \ldots & a_{2 n} \\
\cdot & \cdot & \cdot & \cdot \\
\cdot & \cdot & \cdot & \cdot \\
\cdot & \cdot & \cdot & \cdot \\
1 / a_{1 n} & 1 / a_{2 n} & \ldots & 1
\end{array}\right] \text { (1) }
\end{aligned}
$$

If $\mathrm{c}_{i}$, is judged to be of equal importance as $\mathrm{c}_{j}$, then $\left(\mathrm{a}_{i j}\right)=1$ If $\mathrm{c}_{i}$, is judged to be more important than $\mathrm{c}_{j}$, then $\left(\mathrm{a}_{i j}\right)>1$ If $\mathrm{c}_{i}$, is judged to be less important than $\mathrm{c}_{j}$, then $\left(\mathrm{a}_{i j}\right)<1$ $\left(\mathrm{a}_{i j}\right)=1 / \mathrm{a}_{j i}, \quad(i, j=1,2,3, \ldots, n), \mathrm{a}_{i j} \neq 0$.

Where matrix $A$ represents a reciprocal matrix, $\mathrm{a}_{i j}$ is the inverse of the entry $\mathrm{a}_{k j}$ which indicates the relative importance of $\mathrm{C}_{i}$ compared with attribute $\mathrm{C}_{j}$. As an example, $\mathrm{a}_{12}=3$ indicates that $\mathrm{C}_{1}$ is 3 times as important as $\mathrm{C}_{2}$. In matrix $A$, it becomes the case of assigning the $n$ elements $\mathrm{C}_{l}$, $\mathrm{C}_{2}, \mathrm{C}_{3}, \ldots \mathrm{C}_{n}$ a set of numerical weights $\mathrm{W}_{1}, \mathrm{~W}_{2}, \mathrm{~W}_{3}, \ldots \mathrm{W}_{n}$, that represents the recorded experts' judgments. If $A$ is a consistency matrix, the links between weights $\mathrm{W}_{i}$ and judgments $\mathrm{a}_{i j}$ are given by $\mathrm{W}_{i} / \mathrm{W}_{j}=\mathrm{a}_{i j}$ (for $i, j=1,2,3, \ldots$, $n$ ). Saaty (1990) recommends that the maximum eigenvalue, $\lambda_{\max }$, can be determined as

$$
\lambda_{\max }=\sum_{j=1}^{n} a_{i j}{ }_{W_{j} / W_{i} .}
$$

Where $\lambda_{\max }$ is the principal or maximum eigenvalue of positive real values in judgment matrix, $W_{j}$ is the weight of $j^{\text {th }}$ factor, and $W_{i}$ is the weight of $i^{\text {th }}$ factor.

If $A$ represents consistency matrix, eigenvector $\mathrm{X}$ can be determined as

$$
\left(A-\lambda_{\max } I\right) \mathrm{X}=0
$$

Both AHP and Expert Choice (the software system used to implement AHP) do not impose on the decision makers (in this case, pharmaceutical firm managers) to be perfectly consistent in their judgments, rather a consistency test is performed to normalize inconsistencies among the judges. Saaty (1990) recommends using consistency index (CI) and consistency ratio (CR) to check for the consistency associated with the comparison matrix. A matrix is assumed to be consistent if and only if $a_{i j} * a_{j k}=a_{j k} \forall_{i j k}$ (for all $i, j$, and $k$ ). When a positive reciprocal matrix of order $n$ is consistent, the principal eigenvalue possesses the value $n$. Conversely, when it is inconsistent, the principal eigenvalue is greater than $n$ and its difference will serve as a measure of CI. Therefore, to ascertain that the priority of elements is consistent, the maximum eigenvector or relative weights $/ \lambda_{\max }$ 
can be determined. Specifically, CI for each matrix order $n$ is determined by using (3):

$$
\mathrm{CI}=\left(\lambda_{\max }-\mathrm{n}\right) / \mathrm{n}-1
$$

Where $\mathrm{n}$ is the matrix size or the number of items that are being compared in the matrix. Based on equation (3), the consistency ratio $(\mathrm{CR})$ can be determined as:

$$
\mathrm{CR}=\mathrm{CI} / \mathrm{RI}=\left[\left(\lambda_{\max }-\mathrm{n}\right) / \mathrm{n}-1\right] / \mathrm{RI} \text {. }
$$

Where RI represents average consistency index over a number of random entries of same order reciprocal matrices shown in Table 2. CR is acceptable, if its value is less than or equal to 0.10 . If it is greater than 0.10 , the judgment matrix will be considered inconsistent. To rectify the judgment matrix that is inconsistent, decision-makers' judgments should be reviewed and improved.

Table 1 Reference Values of RI for Different Numbers of n

\begin{tabular}{|c|c|c|c|c|c|c|c|c|c|c|}
\hline $\mathrm{n}$ & $\mathbf{1}$ & $\mathbf{2}$ & $\mathbf{3}$ & $\mathbf{4}$ & $\mathbf{5}$ & $\mathbf{6}$ & $\mathbf{7}$ & $\mathbf{8}$ & $\mathbf{9}$ & $\mathbf{1 0}$ \\
\hline $\mathrm{RI}$ & 0.00 & 0.00 & 0.58 & 0.90 & 1.12 & 1.24 & 1.32 & 1.41 & 1.46 & 1.45 \\
\hline
\end{tabular}

The composite or overall score for each of the four alternative risk management strategies is determined or the purpose of selecting the most appropriate risk treatments with respect to mitigating risk in global supply chain of a pharmaceutical firm. The composite score of the alternatives can be derived by multiplying the relative priorities of an alternative by the relative priorities of the corresponding criteria and added over all criteria. Specifically,

$$
\mathrm{S}_{i}=\sum_{j=1}^{n} \mathrm{w}_{\mathrm{j}} \mathrm{p}_{i j} \text { for } i=1,2, \ldots, \mathrm{n}
$$

Where $S_{i}$ is the composite score for the $i^{\text {th }}$ alternative risk management strategy, $\mathrm{p}_{i j}$ is the score of the $i^{\text {th }}$ alternative risk management strategy with respect to the ${ }_{j}^{\text {th }}$ supply chain risk criterion, and $\mathrm{w}_{j}$ is the priority weight of the $j^{\text {the }}$ supply chain risk criterion in the second level.

Sensitivity analysis (SA) determines the degree to which the overall priorities are sensitive to changes in the importance of criteria. Essentially, SA determines whether small changes in decision makers' opinions or judgments will influence the final priorities and the rankings of the alternatives. The more insensitive or stable the ranking of the alternatives are, the more confident decision makers will become in their proposed selection.

\section{DATA COLLECTION}

A thorough literature review was first conducted to identify risk sources in the pharmaceutical industry. Based on the list of identified risks a survey questionnaire was developed and disseminated to a group of four senior managers, including chief risk officer, supply chain, operations, and procurement managers with more than 15 years of experience for their expert opinions. The chief risk officer led the group discussion on existing and emerging risk sources. In group decisions making, group participants endeavor to attain the same goal and have more in common than in conflict as they work as a group to achieve consensus
(Al-Harbi, 2001). Basak and Saaty (1993) attests that "consensus is a process of general agreement on public issues." Lai et al. (2002) assert that consensus is the reaching of consensus of group participants in constructing a hierarchy and making judgments. Using the AHP-based decision-making approach the group brainstormed and reached a consensus on the relevant risk sources used in this paper. Brainstorming and sharing ideas and insights using a combination of the AHP and Expert Choice in a group setting often results in a more complete representation and understanding of the problems (Al-Harbi (2001). Specifically, in a round-robin manner, the focal firm's group participants provided their opinions and recorded for thorough deliberation. Group participants provided written and individual judgments of the sources of risks and risk management strategies by score aggregation, and discussion. Thus, the opinions expressed in their judgments were considered to be representative of the pharmaceutical focal firm in the risk criteria and risk management options. According to McGrath (1984), opinions or judgments that represent a nominal amount of group agreement are recorded and retained. Al-Harbi (2001) argues that if during the process it is impossible to reach a consensus on a judgment, the group participants may either use some voting technique or take the average or geometric mean of the judgments. However, it was not the case with the focal firm's group participants.

Indeed, a group decision making model enables individual judgments or subject matter expert opinions to be amalgamated and assessed so that a group decision can be successful achieved. Expert Choice, Inc. (n. d) proposed a number of suggestions and recommendations on group decision making. Therefore, because it was a group decisionmaking by the aforementioned senior managers the number of response obtained for the analyses is one. Al-Harbi (2001) asserts that "the AHP allows group decision making, where group members can use their experience, values and knowledge to break down a problem into a hierarchy and solve it by the AHP steps." Hunt (1992) emphasized that the main attributes in three areas, including member, group, and task must exist for group work to be successful.

The approved and most important risks prevalent in the pharmaceutical industry, the focal firm in particular were then used to develop the final survey questionnaire. Thus, the relational data were obtained with the aid of questionnaire administered on a group of supply chain managers within a pharmaceutical firm to determine the order of importance of the supply chain risk criteria. The focal firm with an annual revenue of almost $\$ 40$ million is resident in the Midwestern region of the US. It maintains a workforce of more than 80,000 employees at various manufacturing, distribution, research and development locations globally. As one of the major players in the pharmaceutical industry, it manufactures and markets its pharmaceutical commodities in more than 120 countries. From the hierarchy tree, a questionnaire was developed to enable pairwise comparisons between all the criteria at each level in the hierarchy.

The pairwise comparison process elicits qualitative judgments that indicate the strength of supply chain managers' preference in a specific comparison according to Saaty's 1-9 scale. Indeed, they were requested to respond to several pairwise comparisons where two categories at a time were compared with respect to the goal as well as the major 
criteria. The result of the survey questionnaire technique was then used as input for the AHP. The matrix of pairwise comparisons of the criteria provided by the pharmaceutical firm in the case study is shown in Table 2 . The judgments are entered using the Saaty's pairwise comparison preference scale explained in step 3. The data collected were analyzed with the aid of AHP using Expert Choice Software 11.5.

Table 2 Pairwise Comparison Matrix for Risk Factors

\begin{tabular}{|l|l|l|l|l|l|l|}
\hline GOAL & RLR & OPR & RR & FR & MR & RER \\
\hline RLR & 1 & 3 & 1 & 5 & 3 & 5 \\
\hline OPR & $1 / 3$ & 1 & 1 & 5 & 3 & 3 \\
\hline RR & 1 & 1 & 1 & 2 & 3 & 3 \\
\hline FR & $1 / 5$ & $1 / 5$ & $1 / 2$ & 1 & 1 & 2 \\
\hline MR & $1 / 3$ & $1 / 3$ & $1 / 3$ & 1 & 1 & 1 \\
\hline RER & $1 / 5$ & $1 / 3$ & $1 / 3$ & $1 / 2$ & 1 & 1 \\
\hline
\end{tabular}

\section{RESULTS AND DISCUSSION}

\subsection{Results}

Figure 2 shows the priorities of major criteria with respect to the goal. For the major supply chain risk criteria, regulation/legislation risk is considered the most important followed by operational and reputation risks, while financial, market, and relationship risks rank the lowest. The consistency ratio (CR) of 0.04 is less than 0.10 recommended by Saaty's (1980). Based on Saaty's (1980) recommendation that a CR of 0.10 or less is acceptable, the foregoing pairwise comparisons to derive criterion weights are therefore consistent. Also, Figure 2 shows the priority of each subcriterion with respect to each or its corresponding criterion. Results indicate that exchange rate, $M \& A$, both $R \& D$ and competition, regulatory approval, and both corporate social responsibility and disclosure represent the most important sub-risk criteria.

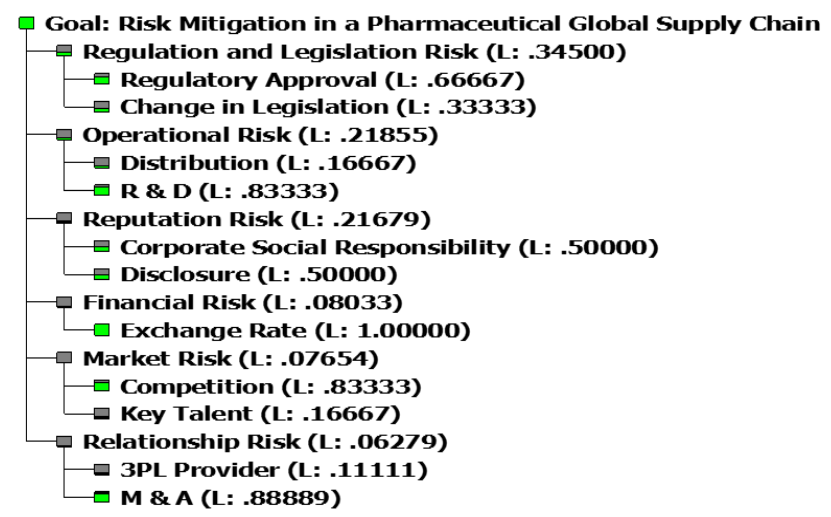

Figure 2 Priorities of Criteria and Sub-Criteria with Respect to the Goal

Based on the major supply chain risk criteria, priority weights of each alternative were evaluated and summarized in Figure 2. For the major supply chain risk criteria, the most important risk regulation and legislation (0.3450). The US Food and Drug Administration's regulation lengthens the process for bringing new pharmaceuticals to market in order to sector to protect healthcare ultimate consumer. Unlike other industries, the pharmaceutical industry is exceedingly regulated to ensure compliance with federal safety laws and to protect public. Following in importance include operational risk (0.2186), reputation risk (0.2168), financial risk (0.0803), market risk (0.0765), and relationship risk (0.0628). For the risk sub-criteria, exchange rate (1.0000) is the most important risk sub-criterion, for the focal pharmaceutical firm. With subsidiaries and operations in many countries around the globe, it has to contend with transaction, translation, economic exposures. Thus, unanticipated exchange rate fluctuations can significantly impact its operations, competitive advantage, and profitability. Following in importance include merger \& acquisition (.8889), research and development (0.8333), regulatory approval $(0.6667)$, corporate social responsibility and disclosure (0.5000), etc.

The summaries of the composite (overall) priority of the five alternative risk management strategies are reported in Table 3. Among the five risk management strategies, reduce risk is the best strategy $(0.3659)$ followed by avoid risk (0.2214), and share risk (0.1705). Therefore, reducing/mitigating risk must be selected as the most preferred risk management strategy to satisfy the pharmaceutical firm's goal. Table 4 reports on the composite priority for the 11 sub-criteria. The composite results for regulatory approval and change in legislation indicate that the best risk management strategy is risk reduction/mitigation (0.353) followed by risk avoidance (0.195), risk sharing (0.183). For distribution and research and development, risk reduction/mitigation (0.349), followed by risk avoidance (0.164). With respect to corporate social responsibility and disclosure (0.377), followed by avoidance risk (0.302). For exchange rate, risk reduction/mitigation $(0.331)$ is most favored relative to risk transfer $(0.285)$ and risk sharing (0.223). Competition and key talent are best managed with risk reduction/mitigation (0.486) and risk avoidance (0.164). With regard to 3PL and merger and acquisition, the most favored risk management option is risk reduction/mitigation (0.503), followed by risk sharing (0.187) and risk avoidance (0.129). Arguably, those pharmaceutical firms able to assess, mitigate and manage portfolio of risks will thrive, prosper, gain competitive position.

\subsection{Sensitivity analysis Results}

Figures $\mathbf{3}-5$ are the gradient sensitivity analysis graphs we use to demonstrate how SA is done in AHP. The gradient sensitivity graphs show the alternatives' priorities with respect to regulation and legislation, operational risk, and reputation risk. The vertical line indicates the attribute's priority with respect to goal, while the diagonal lines are the priorities of the alternatives at each position of the vertical line. In each gradient graph, a series of sensitivity analyses are performed using AHP-based Expert Choice Software to investigate the impact of changing the priority of the criteria on the ranking of the risk management alternatives.

For the gradient sensitivity analysis with respect to regulation and legislation shown in Figure 3, the initial alternative risk management ranking is as follows: 1) reduce risk, 2) share risk, 3) avoid risk, 4) transfer risk, and 5) retain risk. Increasing (decreasing) the priority of regulation and legislation risk in Figure 3 from 0.34 to 0.44 (.24) in Figure 4 and Figure 5, respectively, did not change the choice of the alternative with respect to regulation and legislation risk. Therefore, minimizing the pharmaceutical supply chain risk 
is insensitive or stable to changes in the importance of regulation and legislation risk. Similarly, supply chain managers can perform gradient sensitivity on the rest of the risks to test their robustness.

For the reputation risk depicted in Figure 9, the initial ranking is follows: 1) reduce risk; 2) avoid risk; 3) retain risk; 4) share risk; and 5) transfer risk. Similarly, increasing (decreasing) the priority of reputation risk in Figure 9 from
0.22 to 0.32 (.12) in Figure 10 and Figure 11 (not shown due to limited space), respectively, did not change the initial ranking of risk management options. This means that the environment is insensitive or robust. Therefore, based on the entire gradient sensitivity analyses, the overall priority of alternative is robust or stable to changes in the importance of all the criteria.

Table 3 Composite Score of Five Alternative Risk Management Strategies

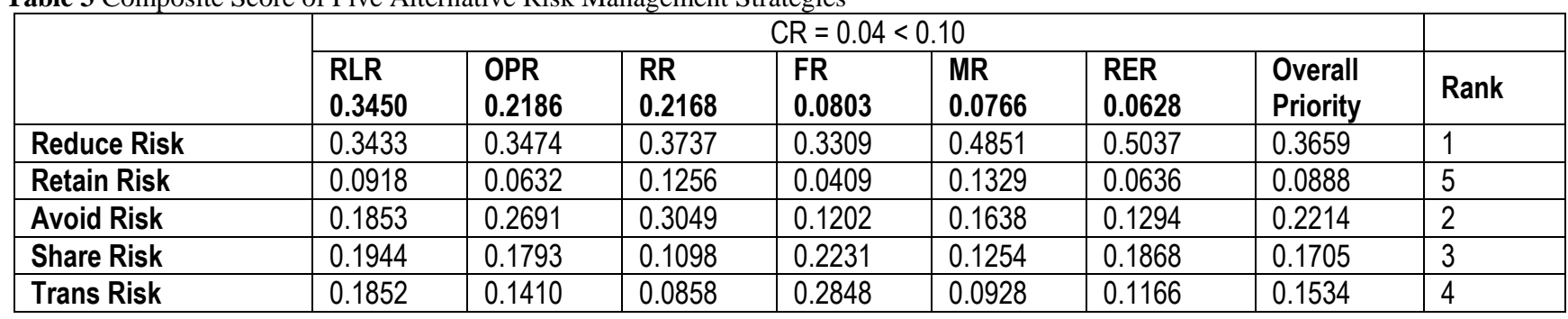

Table 4 Sub-criteria* Composite Score Risk Management Strategies

\begin{tabular}{|c|c|c|c|c|c|c|c|c|c|c|c|}
\hline & RA & $\mathrm{CL}$ & DIS & RD & CSR & DI & ER & CO & KT & 3PL & MA \\
\hline & 0.667 & 0.333 & 0.167 & 0.833 & 0.500 & 0.500 & 1.00 & 0.833 & 0.167 & 0.111 & 0.889 \\
\hline \multirow{2}{*}{$\begin{array}{l}\text { RedR } \\
\text { RedR2 }\end{array}$} & 0.414 & 0.23 & 0.404 & 0.338 & 0.345 & 0.407 & 0.331 & 0.488 & 0.473 & 0.523 & 0.501 \\
\hline & 0.276 & 0.077 & 0.067 & 0.282 & 0.173 & 0.204 & 0.331 & 0.407 & 0.079 & 0.058 & 0.445 \\
\hline \multirow{2}{*}{$\begin{array}{l}\text { RetR } \\
\text { RetR }_{2}\end{array}$} & 0.079 & 0.112 & 0.077 & 0.061 & 0.111 & 0.142 & 0.041 & 0.138 & 0.11 & 0.112 & 0.058 \\
\hline & 0.053 & 0.037 & 0.013 & 0.051 & 0.056 & 0.071 & 0.041 & 0.115 & 0.018 & 0.012 & 0.052 \\
\hline \multirow{2}{*}{$\begin{array}{l}\text { AvoR } \\
\text { AvoR }_{2}\end{array}$} & 0.261 & 0.064 & 0.189 & 0.282 & 0.356 & 0.247 & 0.12 & 0.151 & 0.228 & 0.154 & 0.126 \\
\hline & 0.174 & 0.021 & 0.032 & 0.235 & 0.178 & 0.124 & 0.12 & 0.126 & 0.038 & 0.017 & 0.112 \\
\hline \multirow{2}{*}{$\begin{array}{l}\text { ShaR } \\
\text { ShaR }_{2}\end{array}$} & 0.109 & 0.331 & 0.219 & 0.173 & 0.104 & 0.116 & 0.223 & 0.133 & 0.09 & 0.113 & 0.196 \\
\hline & 0.073 & 0.11 & 0.037 & 0.144 & 0.052 & 0.058 & 0.223 & 0.111 & 0.015 & 0.013 & 0.174 \\
\hline \multirow{2}{*}{$\begin{array}{l}\text { TranR } \\
\text { TranR2 }\end{array}$} & 0.137 & 0.262 & 0.111 & 0.146 & 0.084 & 0.088 & 0.285 & 0.09 & 0.099 & 0.098 & 0.119 \\
\hline & 0.091 & 0.087 & 0.019 & 0.122 & 0.042 & 0.044 & 0.285 & 0.075 & 0.017 & 0.011 & 0.106 \\
\hline$C R<0.10$ & 0.06 & 0.04 & 0.06 & 0.09 & 0.03 & 0.05 & 0.05 & 0.02 & 0.04 & 0.03 & 0.04 \\
\hline
\end{tabular}

Table 5 Final Sub-criteria Risk Composite Risk Management Strategies

\begin{tabular}{|l|l|l|l|l|l|l|l|l|l|}
\hline & RA & CL & Priority & DIS & RD & Priority & CSR & DI & Priority \\
\hline RedR & 0.276 & 0.077 & $\mathbf{0 . 3 5 3}$ & 0.067 & 0.282 & $\mathbf{0 . 3 4 9}$ & 0.173 & 0.204 & $\mathbf{0 . 3 7 7}$ \\
\hline RetR & 0.053 & 0.037 & $\mathbf{0 . 0 9}$ & 0.013 & 0.051 & $\mathbf{0 . 0 6 4}$ & 0.056 & 0.071 & $\mathbf{0 . 1 2 7}$ \\
\hline AvoR & 0.174 & 0.021 & $\mathbf{0 . 1 9 5}$ & 0.032 & 0.235 & $\mathbf{0 . 2 6 7}$ & 0.178 & 0.124 & $\mathbf{0 . 3 0 2}$ \\
\hline ShaR & 0.073 & 0.11 & $\mathbf{0 . 1 8 3}$ & 0.037 & 0.144 & $\mathbf{0 . 1 8 1}$ & 0.052 & 0.058 & $\mathbf{0 . 1 1}$ \\
\hline TraR & 0.091 & 0.087 & $\mathbf{0 . 1 7 8}$ & 0.019 & 0.122 & $\mathbf{0 . 1 4 1}$ & 0.042 & 0.044 & $\mathbf{0 . 0 8 6}$ \\
\hline
\end{tabular}

Table 5 Final Sub-criteria Risk Composite Risk Management Strategies (Con't)

\begin{tabular}{|l|l|l|l|l|l|l|l|l|}
\hline & ER & Priority & CO & KT & Priority & 3 PL & MA & Priority \\
\hline RedR & 0.331 & $\mathbf{0 . 3 3 1}$ & 0.407 & 0.079 & $\mathbf{0 . 4 8 6}$ & 0.058 & 0.445 & $\mathbf{0 . 5 0 3}$ \\
\hline RetR & 0.041 & $\mathbf{0 . 0 4 1}$ & 0.115 & 0.018 & $\mathbf{0 . 1 3 3}$ & 0.012 & 0.052 & $\mathbf{0 . 0 6 4}$ \\
\hline AvoR & 0.12 & $\mathbf{0 . 1 2}$ & 0.126 & 0.038 & $\mathbf{0 . 1 6 4}$ & 0.017 & 0.112 & $\mathbf{0 . 1 2 9}$ \\
\hline ShaR & 0.223 & $\mathbf{0 . 2 2 3}$ & 0.111 & 0.015 & $\mathbf{0 . 1 2 6}$ & 0.013 & 0.174 & $\mathbf{0 . 1 8 7}$ \\
\hline TraR & 0.285 & $\mathbf{0 . 2 8 5}$ & 0.075 & 0.017 & $\mathbf{0 . 0 9 2}$ & 0.011 & 0.106 & $\mathbf{0 . 1 1 7}$ \\
\hline
\end{tabular}




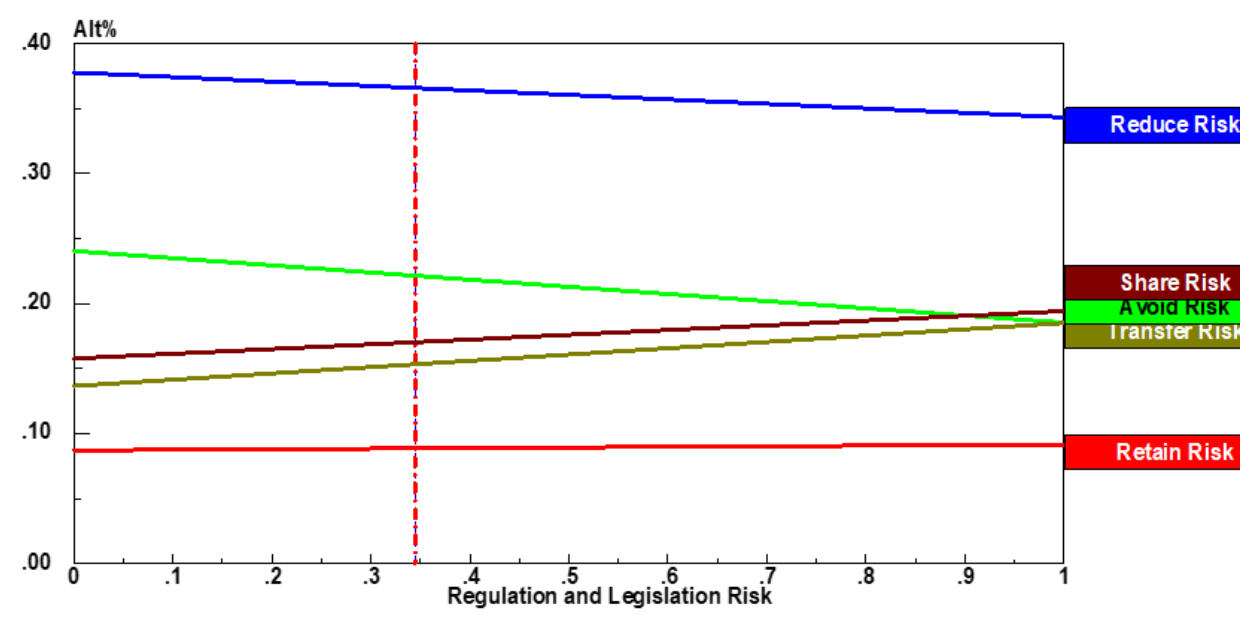

Figure 3 Gradient Sensitivity Analysis - Original

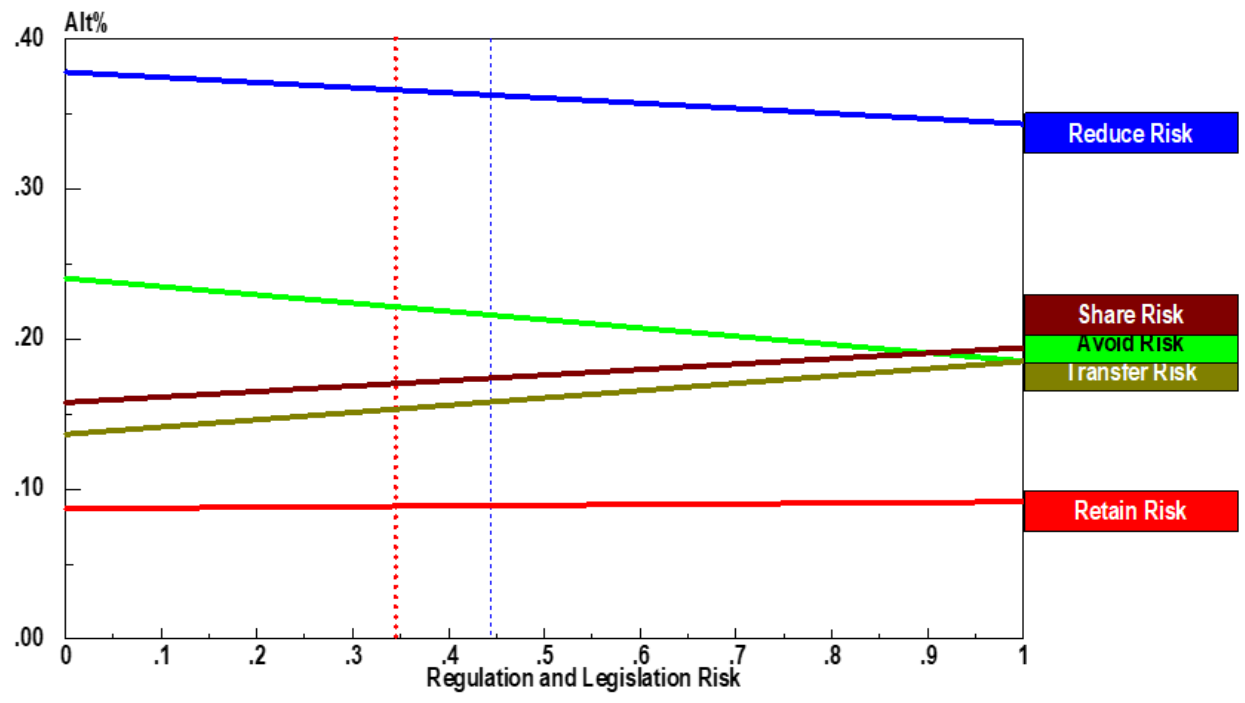

Figure 4 Gradient Sensitivity Analysis - Increase Scenario

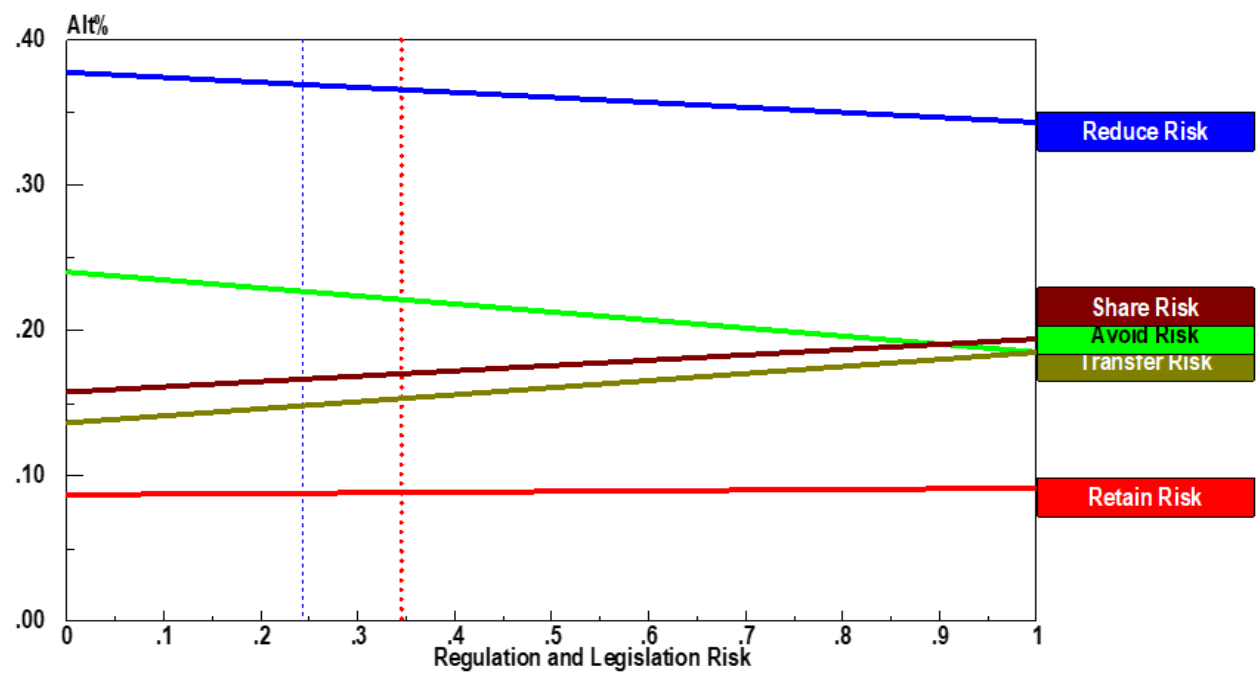

Figure 5 Gradient Sensitivity Analysis - Decrease Scenario 


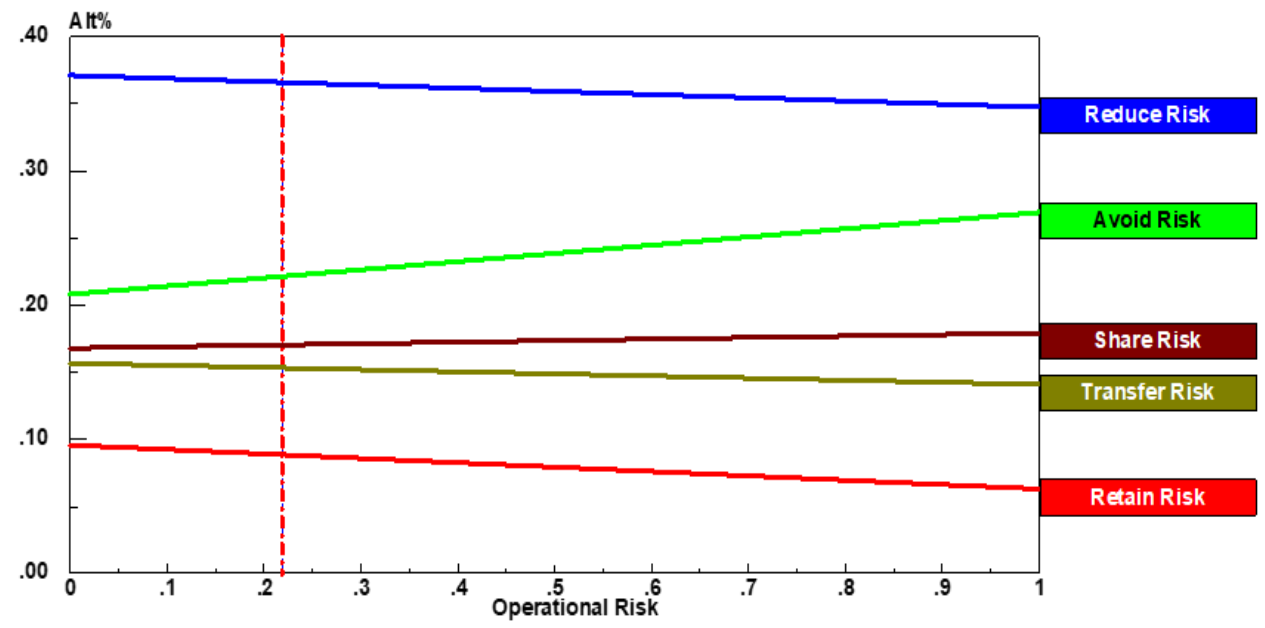

Figure 6 Gradient Sensitivity Analysis for Operational Risk - Original

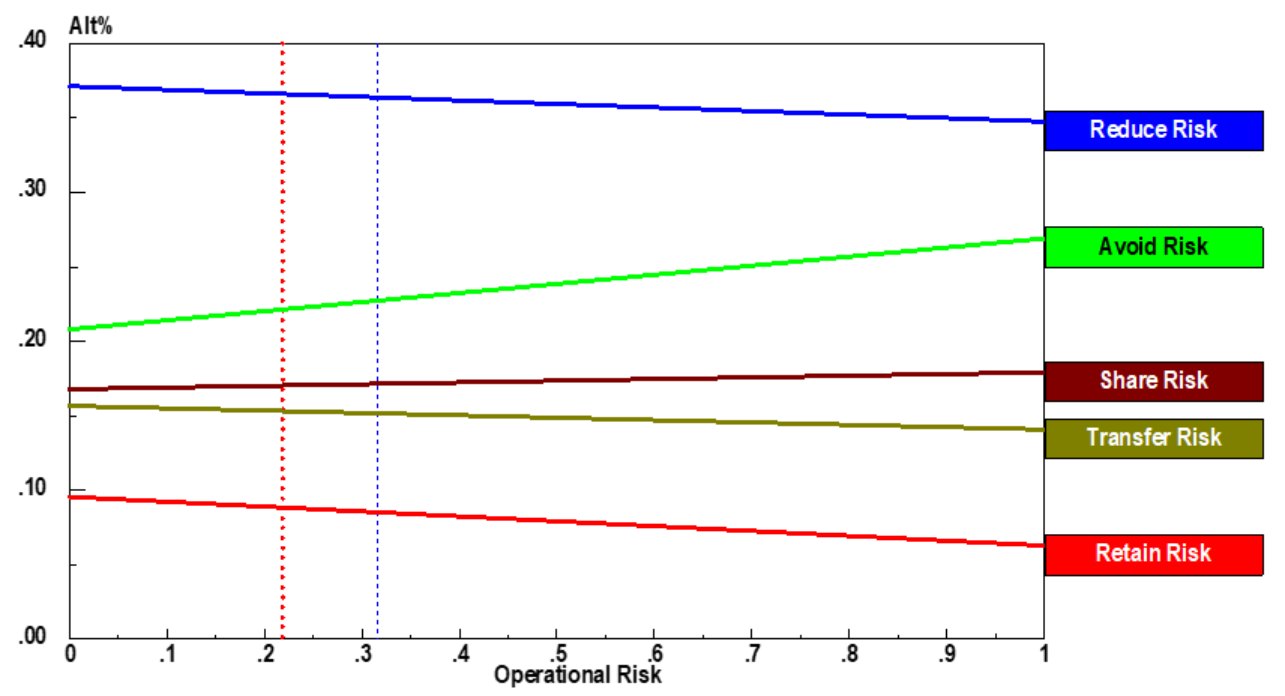

Figure 7 Gradient Sensitivity Analysis - Increase Scenario

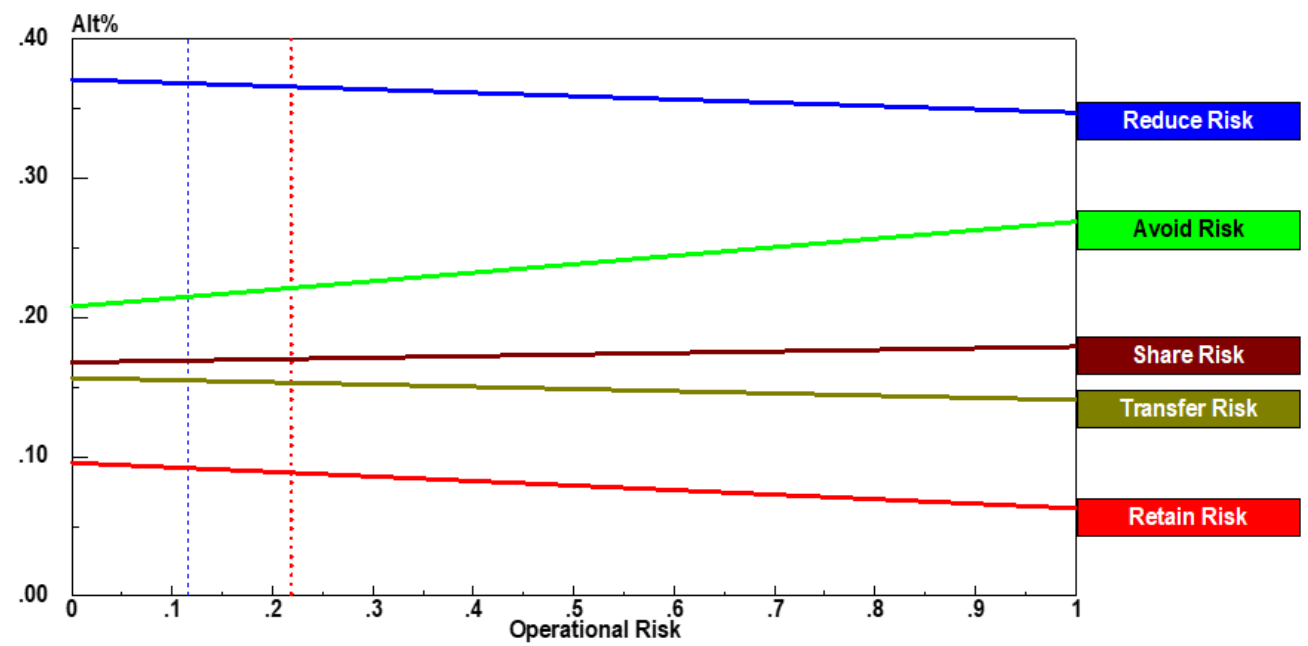

Figure 8 Gradient Sensitivity Analysis - Decrease Scenario 


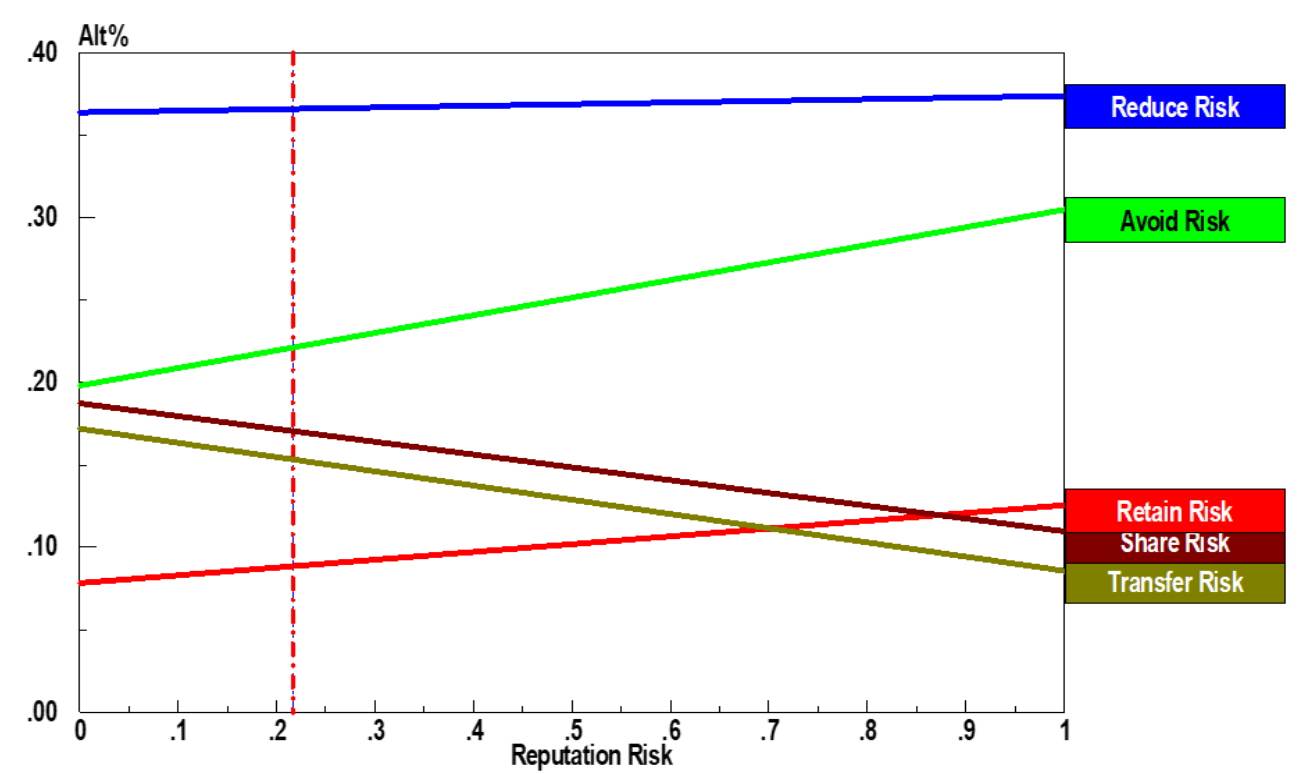

Figure 9 Gradient Sensitivity Analysis for Reputation Risk

\section{CONCLUSION AND MANAGERIAL IMPLICATIONS}

Because of the need to take advantage of new markets and cost opportunities pharmaceutical global supply chains have been stretched more than ever before. This stretch has equally produce global supply chains that are more complex and vulnerable to increasing risks. Supply chain risk management is an important problem confronting the pharmaceutical firm as identifying sources of risks and mitigating them represent a long term investment. Risk management is a multi-person, multi-criteria decision problem. A group decision-making process can be improved by a systematic and logical method to evaluate risk and risk management priorities based on opinions judgments of supply chain managers and/or chief supply chain risk officers within the pharmaceutical. Thus, multi-criteria decision making methodology such as AHP can be beneficial in actively involving supply chain risk officers with diverse conflicting objectives to reach a consensus decision. This paper leverages AHP model to empirically investigate its applicability in supply chain risk management for the focal firm. The AHP model proved useful in the group decision making and in identifying risks and determining the best risk mitigation strategy. Results indicate that regulation and legislation was the most important risk followed by production risk. For risk management strategies, mitigate/reduce risk strategy was the best closely followed by avoid risk strategy. Arguably for the many pharmaceutical firms, managing global supply chain risk has become prominent in their business operation agenda. To meet regulatory compliance, ensure consumer health and safety, grow profit, and ensure long-term success for its pharmaceuticals, global supply chain risk management has become undoubtedly imperative.

This paper makes significant contributions to operations and supply chain management literature. 1) modelling of enterprise risk management strategies in the focal firm utilizing AHP model. Results of this study will help to guide enterprise risk management (supply chain managers) in choosing appropriate measures to reduce/mitigate risk and offers a number of future research directions. Furthermore, it provides valuable insight for managers in terms of the imperative of identify most vital risk sources attached to pharmaceutical operations and supply chain, designing effective and predictive enterprise risk management strategies. 2) Identification of three most underlying factors of the operations and supply chain risks inherent in the focal pharmaceutical firm. The measurement may be used to assess operations and supply chains risks based on their potential impacts in different context. Results emanating from this study is important for other pharmaceutical firms in the industry as they face similar risks such as FDA increased regulatory approval and guidelines regarding drug quality, efficacy, and safety. Indeed, the results accruing from this study will be valuable to other pharmaceutical firms in a number of ways, including supporting supply chain managers on how to identify sources of risks and the application of multi-criteria decision making approach such as the analytic hierarchy process to develop proactive and predictive enterprise risk management.

Arguably, it is envisaged that the findings in this paper if adopted can help to strengthen similar pharmaceutical firms' enterprise risk management, improve their resilience to sudden disruptive risks, and operate at best-practice performance levels. Furthermore, for the focal firm and others in the pharmaceutical industry, this study will deepen senior managers' understanding of the disruptive impact of operations and supply chain risks, how to redesign and leverage an adaptive AHP model to mitigate and manage known-unknown risks. Specifically, the findings will allow the focal firm and other firms' managers as an input to design an adaptive and an effective use of the AHP as a predictive enterprise risk management tool. The work empirically can inform decision makers on the imperatives of managing operations and supply chains, and contributes to the existing literature by filling the information gap on the use of AHP in modeling risk in pharmaceutical supply chain operations, and extending and augmenting previous studies in the context of pharmaceutical operations and supply chain. 3) A pharmaceutical supply chain risk management that is cross- 
functional-team based can be established and charged with regularly maintaining risk register and auditing risk leveraging the hierarchy structure and the AHP model brought to bear in this paper. Finally, 4) a practical guideline for evaluating and using gradient sensitivity analysis to test robustness of the supply chain risk ranking in a firm pharmaceutical context.

For future research, fuzzy AHP, Bayesian model, or a combination of AHP and goal programming could be leveraged to model enterprise risk management in the pharmaceutical industry operations and supply chains. This would improve the effectiveness of operations and supply chain risk management in a particular context. Arguably, it will support operations and supply chain managers in focusing their attention and design predictive enterprise risk management strategies based on the relative significance of risk attributes in their firms.

\section{REFERENCES}

Al-Harbi, K. M. A. (2001). Application of the AHP in project management. International Journal of Project Management 19, pp. 19-27

Atthirawong, W. and MacCarthy, B. (2005). An Application of the analytic hierarchy process to International Location Decision-Making. Proceedings of the $7^{\text {th }}$ Cambridge Research Symposium on International Manufacturing Symposium: Restructuring Global Manufacturing, Cambridge, England: University of Cambridge, pp. 1-18.

Basak, I. and Saaty, T. (1993). Group decision making using analytic hierarchy process. Mathematical Computing Modelling 17(4-5), pp. 101-109.

Bandyopadhyay, K., Mykytyn, P. and Mykytyn, K. (1999). A framework for integrated risk management in information technology. Management Decision 37(5), pp. 437-44.

Barry, J. (2004). Supply chain risk in an uncertain global supply chain environment. International Journal of Physical Distribution \& Logistics Management 34(9), pp. 695-697.

Belton, V. and Gear, T. (1983). On a shortcoming of Saaty's method of analytic hierarchy. Omega 11(3), pp. 228-30.

Blake, J. T., Reibman, A. L. and Trivedi, K. S. (1988). Sensitivity analysis of reliability and performability measures for multiprocessor Systems. ACM SIGMETRICS conference on Measurement and modeling of computer systems Santa Fe, New Mexico, United States.

Castillo, E., R. Mínguez, R. and Castillo, C. (2006). Sensitivity analysis in optimization and reliability problems. In ESREL.

Breen, L. (2008). A preliminary examination of risk in the pharmaceutical supply chain (SC) in the National Health Service (NHS). Journal of Service Science \& Management 1 , pp. 193-199.

Calantone, R.A., Di Benedetto, R.A., Meloche, M. (1989). The analytic hierarchy process as a technique for retail store location selection. Journal of Business Strategies 6(1), 6174.

Cavinato, J. L. (2004). Supply chain logistics risks: from the back room to the board room. International Journal of Physical Distribution \& Logistics Management 34(5), pp. 383-387.

Chan, C. K., Seow, S. G. and Tam, K. (2002). Foreign exchange risk and firm value: an analysis of US pharmaceutical firms. Managerial Finance 28(3), pp. 52-72.

Christopher, M. and Lee, H. (2004). Mitigating supply chain risk through improved confidence. International Journal of Physical Distribution \& Logistics Management 34 (5), pp. 388-396.

Dyer, J.S. and Wendel, R.E. (1985). A critique of analytic hierarchy process. Working Paper 84/85-4-24, Department of Management, The University of Texas at Austin.
Dyer, R.F. and Forman, E. H. (1991). An Analytic Approach to Marketing Decisions, Prentice Hall, Englewood Cliffs.

Eschenbach, T. G. (1992). Spiderplots versus tornado diagrams for sensitivity analysis. Interfaces 22 (6), pp. 40-46.

Erkut, E and Tarimcilar, M. (1991). On sensitivity analysis in the analytic hierarchy process. IMA Journal of Management Mathematics 3(1), pp. 61-83.

Expert Choice, Inc. (n. d). Expert Choice software and manual. 4922 Elsworth Ave., Pittsburgh, PA 15213, USA.

Fiacco, A.V. (2003). Introduction to sensitivity and stability analysis in nonlinear programming. Annals of Operations Research 27, pp. 215-236.

Flanagan, R and Norman, G. (1993), Risk Management and Construction, Blackwell Scientific Publications, London.

Gaudenzi, B. and Borghesi, A. (2006). Managing risks in the supply chain using the AHP method. The International Journal of Logistics Management 17(1), pp. 114-136.

Hallikas, J. Virolainen, V. and Tuominen, M. (2002). Risk analysis and assessment in network Environments: A Dyadic Case Study. International Journal of Production Economics 78(1), pp. 45-55.

Hendricks, K. B. and Singhal, V. R. (spring 2005). An empirical analysis of the effect of supply chain disruptions on long-run stock price performance and equity risk of the firm. Production and Operations Management 14(1), pp. 35-52.

Hillman, M. and Keltz, H. (January 2007). Managing risk in the supply chain - a quantitative study. AMR Research Report 122.

Hunt, J.W. (1992). Groups in Organizations. In Managing People at Work. New York: McGraw-Hill.

Hunter, L. M., Kasouf, C. J., Celuch, K. G., \& Curry, K. A (2004). A classification of business-to-business buying decisions: risk importance and probability as a framework for e-business benefits. Industrial Marketing Management 33(2), pp. 14554

Jüttner, U., Peck, H. and Christopher, M. (2003). Supply chain risk management: outlining an agenda for future research. International Journal of Logistics: Research and Applications 6 (4), pp. 197-210.

Kleindorfer, P.R. and Saad, G. H. (spring 2005). Managing disruption risks in supply chains. Production and Operations Management 14(1), pp. 53-68.

KPMG. (2005). Risk management in the pharmaceutical industry. Retrieved September 18, 2006, from http://www.worldcongress.com/events/nw700pdf/thoughtLe adership/KPMG-Pressure-Points-Web.pdf

Lai, V. S., Wong, B. K., and Cheung, W. (2002). Group decision making a multiple-criteria environment: a case using the AHP in software selection. European Journal of Operational Research, 137, pp. 134-144

Lee, H. L, Padmanabhan, V. and Wang, S. (1997). The bullwhip effect in supply chains. Sloan Management Review 38(3), pp. 93-102.

Lowe, J and Whitworth, T. (1996), Risk management and major construction projects, CIB W65 (in conjunction with W92) International Symposium for the Organization and Management of Construction: Shaping Theory and Practice, Glasgow, Scotland, pp. 891-899.

Lowery, R. (2004), supply chain: risky business. Logistics Today, pp. 1-4.

Min, H. (1992). Selection of software: the analytic hierarchy process. International Journal of Physical Distribution \& Logistics Management 22(1), pp. 42-52.

Norrman, A. and Jansson, U. (2004). Ericsson's proactive supply chain risk management approach after a serious sub-supplier accident. International Journal of Physical Distribution \& Logistics Management 34 (5), pp. 424-456.

O'Brien, P. and Joyce, G. (2007). Risk Management: Supply Chain Risk-Are you the Weakest Link? LinkResQ Ltd, pp. 1-6.

Perez, P. (1995). Some comments on Saaty's AHP. Management 
Science 41 (6), pp. 1091-1095.

Rappaport, A. (1967). Sensitivity analysis in decision making. The Accounting Review July, pp. 441-456.

Ross, M.E. and Nydick, R.L. (1994). Structuring the selection process of licensing candidates' in the pharmaceutical industry using the analytic hierarchy Process. Journal of Pharmaceutical Marketing and Management 8(1), pp. 21-36.

Saaty, T.L. (1980), The analytic hierarchy process. New York: McGraw-Hall

Samson, D. (1988). Managerial decision analysis. Homewood: Irwin.

Steenland, K. and Greenland, S. (2004). Monte carlo sensitivity analysis and bayesian analysis of smoking as an unmeasured confounder in a study of silica and lung cancer. American Journal of Epidemiology160(4), pp. 384-392.

Tang, C. S. (2006). Perspectives in supply chain risk management. International Journal of Production Economics 103(2), pp. 451-488.

Trkman, P. and McCormack, K. (2009). Supply chain risk in turbulent environments - a conceptual model for managing supply chain network risk. International Journal of Production Economics 119(2), pp. 247-258.

Towill, D. R. (2005). The impact of business policy on bullwhip induced risk in supply chain management. International Journal of Physical Distribution \& Logistics Management, 35(8), pp. 555-575.

Triantaphyllou, E and Sánchez, A. (Winter 1997). A sensitivity analysis approach for some deterministic multi-criteria decision making methods. Decision Sciences 28(1), pp. 151194.

Trueman, R. E. (1974). An introduction to quantitative methods for decision making. New York: Holt, Rinehart and Winston, Inc.

Wood, S., Dunn, R., Nelson, M., Servi, L., Schniepp, S. J. (2008). Risk management within the global supply chain. Pharmaceutical Technology, October 1.

Yates, J. F. and Stone, E. (1992), The risk construct, in Yates, J.F. (Ed.), risk taking behavior, John Wiley and Sons, New York, NY.

Zsidisin, G.A., Ellram, L.M., Carter, J.R. and Cavinato, J.L. (2004). Analysis of supply risk assessment techniques. International Journal of Physical Distribution \& Logistics Management 34(5), pp. 397-413.

Chris I. Enyinda is a professor of marketing, international business, and operations/supply chain management. He was the founding chair of the Department of Marketing and International Business, School of Business Administration, Canadian University Dubai (CUD). Before joining CUD in August 2012, Chris was a professor and the coordinator of logistics/supply chain management and international business, College of Business and Public Affairs at Alabama A\&M University (AAMU), Huntsville. He was AAMU Faculty Senate president and was a member of the board of trustees. Chris was the president of the International Academy of African Business and Development. He holds a PhD in logistics/operations and supply chain management from North Dakota State University, Fargo. He also holds a PhD in applied economics and marketing from the University of Tennessee, Knoxville. He holds an MBA (marketing and management) and MS (economics/management) from AAMU. He has published scores of papers in a number of journals and peer reviewed proceedings. He has received many outstanding and/or best paper awards. His areas of research interests, consulting, and corporate training include marketing and supply chain operations interface, logistics/operations and supply chain management, project management, purchasing and supply management, health care and pharmaceutical marketing, enterprise risk management, and change management. 